\title{
Pengaruh Dosis Mulsa Ampas Tebu terhadap Pertumbuhan dan Hasil beberapa Varietas Bawang Merah (Allium ascalonicum $\mathbf{L}$.) \\ Effect of Dose Bagasse Mulch on The Growth and Yield Some varieties of Shallot (Allium ascalonicum L.)
}

\author{
Samsia Nst ${ }^{1}$, Mardhiah Hayati ${ }^{1}$, Erita Hayati ${ }^{1}$ \\ ${ }^{1}$ Program Studi Agroteknologi, Fakultas Pertanian, Universitas Syiah Kuala
}

\begin{abstract}
Abstrak. Penelitian ini bertujuan untuk mengetahui pengaruh dosis mulsa ampas tebu dan varietas bawang merah serta interaksi antara keduanya terhadap pertumbuhan dan hasil tanaman bawang merah. Penelitian ini dilaksanakan di Kebun Percobaan Fakultas Pertanian Universitas Syiah Kuala yang berlangsung dari bulan Juli sampai September 2017. Penelitian ini menggunakan Rancangan Acak Kelompok pola faktorial $3 \times 3$ dengan 3 kali ulangan. Faktor pertama adalah dosis mulsa ampas tebu dengan 3 taraf (5, 10 dan 15 ton/ha). Faktor kedua adalah varietas dengan 3 taraf (Bima Brebes, Vietnam dan Bangkok). Hasil penelitian menunjukkan bahwa dosis mulsa ampas tebu berpengaruh sangat nyata terhadap tinggi tanaman umur 10, 20 dan 30 HST, berpengaruh tidak nyata terhadap jumlah umbi per rumpun, jumlah anakan per rumpun, diameter umbi, bobot berangkasan basah, bobot basah umbi, bobot berangkasan kering, bobot kering umbi, serta potensi hasil bawang merah. Pertumbuhan dan hasil tanaman bawang merah terbaik dijumpai pada dosis mulsa ampas tebu 15 ton/ha. Varietas bawang merah berpengaruh sangat nyata terhadap semua peubah yang diamati. Penggunaan varietas terbaik dijumpai pada varietas Vietnam. Hasil penelitian menunjukkan bahwa terdapat interaksi yang tidak nyata antara dosis mulsa ampas tebu dengan varietas bawang merah terhadap semua peubah.
\end{abstract}

Kata kunci: Mulsa Ampas Tebu, Varietas, Bawang Merah, Pertumbuhan dan Hasil

\begin{abstract}
This study aimed to determine the effect of best dose mulch bagasse, varieties and interaction between the bagasse mulch with variety to growth and yield of the shallot. This research was conducted in Experimental Farm Agricultural Faculty of Syiah Kuala University, from July toSeptember 2017. This study used a randomized block design factorial $3 \times 3$ with three duplications. The first factor is the dose bagasse mulch 3 levels $\left(5,10\right.$ and $\left.15 \mathrm{tha}^{-1}\right)$. The second factorvariety of shallot 3 levels (Bima Brebes, Vietnam and Bangkok). The results showed that the dose of bagasse mulch very significant effect on plant height age 10, 20 and 30 DAP, not significant effect on number of tillers per clump, number of bulb, bulb diameter, wet stover weight, wet bulb weight, dry stover weight, dry bulb weight, anda potential yield. The growth and yield of the best shallot seen in dose bagasse mulch $15 \mathrm{t} \mathrm{ha}^{-1}$. The variety of shallot has very significant effect on all variables. The best use of variety is found in Vietnam varieties. The result showed that there was no significant interaction between the bagasse mulch withvariety against all variables.
\end{abstract}

Keywords: Bagasse Mulch, Variety, Shallot, Growth and Yield

\section{PENDAHULUAN}

Bawang merah (Allium ascalonicum L.) merupakan salah satu komoditas tanaman hortikultura yang banyak dikonsumsi sebagai campuran bumbu masak. Bawang merah juga dijual dalam bentuk olahan seperti ekstrak bawang merah, bubuk, minyak atsiri, bawang goreng bahkan sebagai bahan obat untuk menurunkan kadar kolesterol, gula darah, mencegah penggumpalan darah, menurunkan tekanan darah serta memperlancar aliran darah. Potensi pengembangan bawang merah masih terbuka lebar tidak saja untuk kebutuhan dalam negeri tetapi juga luar negeri (Suriani, 2012).

Produksi bawang merah nasional tahun 2015 sebesar 1.229.184 ton, mengalami peningkatan pada tahun 2016 menjadi 1.446 .860 ton. Produksi bawang merah di Provinsi Aceh juga mengalami peningkatan yaitu tahun 2015 sebesar 5.739 ton dan pada tahun 2016 6.725 ton (BPS dan Direktorat Jenderal Hortikultura, 2016). 
Produksi bawang merah mengalami peningkatan setiap tahun pada skala nasional, akan tetapi hal tersebut belum mampu mengimbangi peningkatan permintaan bawang merah secara nasional, seiring dengan bertambahnya jumlah penduduk dan berkembangnya industri olahan. Konsumsi bawang merah di Indonesia diperkirakan mencapai 1.608 .000 ton per tahun (Direktorat Jenderal Hortikultura, 2014).

Untuk mengatasi masalah tersebut ada beberapa hal yang perlu diperhatikan agar produksi yang diharapkan dapat tercapai. Sistem budidaya bawang merah perlu ditangani secara khusus sehingga dapat meningkatkan produksi bawang merah. Selain sistem budidaya, faktor lingkungan juga berpengaruh terhadap pertumbuhan dan perkembangan tanaman. Bawang merah tidak tahan kekeringan karena akarnya yang pendek. Salah satu upaya manipulasi lingkungan tanaman agar ketersediaan air tetap ada yaitu dengan pemberian mulsa.

Pemulsaan merupakan salah satu cara untuk memperbaiki tata udara tanah dan tersedianya air bagi tanaman. Mulsa berperan penting dalam meminimalkan kerugian akibat radiasi matahari dari evaporasi (penguapan air tanah) yang dapat mengurangi kecepatan penguapan yang mampu menurunkan suhu tanah sehingga ketersediaan air tetap memadai untuk dapat mengoptimalkan pertumbuhan dan perkembangan tanaman. Selain itu pemberian mulsa dapat mempercepat pertumbuhan tanaman yang baru ditanam (Novayana et al., 2015).

Ampas tebu merupakan limbah hasil samping dari proses ekstraksi (pemerahan) cairan tebu yang keadaannya belum dimanfaatkan secara maksimal. Dari satu pabrik dihasilkan ampas tebu sekitar 35\% - 40\% dari berat tebu yang digiling (Indriani dan Sumiarsih, 1992) karena jumlahnya yang melimpah maka perlu dimanfaatkan secara maksimal agar dapat mengurangi limbah. Ampas tebu mengandung air $48-52 \%$, gula $3,3 \%$ dan serat $47,7 \%$ (Husin, 2007).

Hasil penelitian Hayati et al. (2010) menyatakan bahwa akibat pemberian mulsa jerami, mulsa ampas tebu dan mulsa sekam padi dapat meningkatkan pertumbuhan dan produksi tanaman jagung. Hasil terbaik diperoleh dengan pemberian mulsa sekam padi kemudian disusul oleh pemberian mulsa ampas tebu dan produksi terendah dihasilkan dengan pemberian mulsa jerami. Parlindungan dan Tampubolon (2015) juga menyatakan tentang pengaruh pola pengolahan tanah dan mulsa ampas tebu terhadap beberapa sifat fisika tanah dan produksi biji kedelai menyatakan bahwa produksi biji kedelai tertinggi diperoleh dengan pemberian mulsa ampas tebu 15 ton/ha yaitu 1,90 ton/ha sedangkan produksi kedelai tanpa pemberian mulsa ampas tebu adalah 1,49 ton/ha.

Faktor lain yang menyebabkan produksi bawang merah rendah adalah pemilihan benih yang tidak sesuai. Benih menjadi salah satu faktor utama yang menjadi penentu keberhasilan dalam budidaya tanaman. Menurut FAO, peningkatan campuran varietas lain dan menurunnya produksi sekitar $2,6 \%$ tiap generasi pertanaman merupakan akibat dari penggunaan benih yang kurang terkontrol mutunya. Saat ini kondisi perbenihan bawang merah di Indonesia perlu mendapatkan perhatian yang lebih serius. Sulitnya mendapatkan benih bawang merah karena keterbatasan varietas unggul lokal, membuat petani memilih untuk mengembangkan varietas asal impor (Basuki, 2005).

Adapun tujuan dari penelitian ini adalah untuk mengetahui pengaruh dosis mulsa ampas tebu dan varietas bawang merah serta interaksi antara keduanya terhadap pertumbuhan dan hasil tanaman bawang merah.

\section{METODE PENELITIAN}

Penelitian ini dilaksanakan di Kebun Percobaan Fakultas Pertanian Universitas Syiah Kuala Darussalam Banda Aceh, pada bulan Juli sampai September 2017. Bahan yang digunakan dalam penelitian ini adalah bibit tanaman bawang merah varietas Bima Brebes, 
Vietnam, dan Bangkok masing-masing sebanyak 378 umbi, ampas tebu sebanyak 48,9 kg, pupuk kandang sebanyak 97,2 kg, pupuk NPK sebanyak 972 g. Adapun alat-alat yang digunakan adalah cangkul, garu, meteran, tali rafia, gembor, kamera, jangka sorong, timbangan digital, papan nama serta alat tulis.

Rancangan percobaan yang digunakan pada penelitian ini adalah Rancangan Acak Kelompok (RAK) pola faktorial $3 \times 3$ dengan 2 faktor. Adapun faktor pertama yaitu dosis mulsa ampas tebu (D) yang terdiri dari 3 taraf, yaitu: $\mathrm{D}_{1}=5$ ton/ha $(0,9 \mathrm{~kg} / \mathrm{bedeng}), \mathrm{D}_{2}=10$ ton/ha $(1,8 \mathrm{~kg} /$ bedeng $)$ dan $\mathrm{D}_{3}=15$ ton/ha $(2,7 \mathrm{~kg} / \mathrm{bedeng})$. Faktor kedua adalah varietas $(\mathrm{V})$ yang terdiri dari tiga taraf, yaitu: $\mathrm{V}_{1}=$ Bima Brebes, $\mathrm{V}_{2}=$ Vietnam dan $\mathrm{V}_{3}=$ Bangkok. Terdapat 9 kombinasi perlakuan, masing-masing perlakuan diulang sebanyak 3 kali, sehingga diperoleh 27 satuan percobaan. Masing-masing satuan percobaan terdiri dari 5 tanaman sampel. Analisis data dilakukan dengan uji $\mathrm{F}$, apabila analisis ragam menunjukkan pengaruh yang nyata, maka dilanjutkan dengan Uji Beda Jujur (BNJ) pada taraf 5\%.

\section{Pelaksanaan penelitian}

Pengolahan tanah dilakukan dengan mencangkul tanah untuk pembuatan bedeng dengan ukuran $140 \mathrm{~cm} \times 120 \mathrm{~cm}$ sebanyak 27 bedengan dengan jarak tanam $20 \mathrm{~cm} \times 20 \mathrm{~cm}$, jarak antar bedengan $30 \mathrm{~cm}$ dan jarak antar blok $40 \mathrm{~cm}$. Selanjutnya pemberian pupuk kandang sebanyak 20 ton/ha (3,6 kg/bedeng) dengan cara ditaburkan di atas bedengan kemudian dicangkul dengan tanah samapai merata. Sebelum ditanam, bibit bawang merah yang dipotong sepertiga bagian kemudian dilakukan penanaman. Setelah penanaman, dilakukan pemupukan NPK sebanyak $200 \mathrm{~kg} / \mathrm{ha}$ (36 g/bedeng) secara larikan. Pemupukan sebaiknya dilakukan pada sore hari agar tidak terjadi penguapan dan segera disiram agar pupuk dapat larut untuk diserap oleh tanaman.

\section{Pemberian Mulsa}

Pemberian mulsa ampas tebu dilakukan setelah penanaman bawang merah sesuai dengan perlakuan. Masing-masing perlakuan terdiri dari sembilan bedeng dengan dosis masing-masing 0,9 kg/bedeng, 1,8 kg/bedeng dan 2,7 kg/bedeng dengan cara dihamparkan di atas permukaan tanah pada bedengan secara merata.

\section{Pemanenan}

Pemanenan bawang merah dilakukan dengan melihat beberapa kriteria panen yaitu, $60 \%$ daun sudah rebah, umbi sudah dua pertiga daun dan batang sudah nampak menguning dan layu, umbi bawang merah sudah terlihat di permukaan tanah, umbi sudah terlihat mengkilap dan keras ketika ditekan serta sudah mengeluarkan bau khas bawang merah. Pemanenan dilakukan dengan mencabut keseluruhan tanaman, baik umbi maupun daun agar umbi tidak tertinggal di dalam tanah.

Peubah yang diamati adalah tinggi tanaman pada umur 10, 20 dan 30 HST, jumlah anakan per rumpu, jumlah umbi per rumpun, diameter umbi, bobot berangkasan basah, bobot basah umbi, bobot berangkasan kering, bobot kering umbi dan potensi hasil.

\section{HASIL DAN PEMBAHASAN}

\section{Pengaruh Dosis Mulsa Ampas Tebu terhadap Pertumbuhan dan Hasil Tanaman Bawang Merah}

Hasil uji F ( Lampiran 1) menunjukkan bahwa mulsa ampas tebu berpengaruh sangat nyata terhadap tinggi tanaman 10, 20 dan 30 HST, berpengaruh tidak nyata terhadap jumlah umbi per rumpun, jumlah anakan per rumpun, diameter umbi, bobot berangkasan basah, bobot basah umbi, bobot berangkasan kering, bobot kering umbi, serta potensi hasil bawang merah. 
Hasil penelitian menunjukkan bahwa dosis mulsa ampas tebu berpengaruh sangat nyata terhadap tinggi tanaman bawang merah umur 10, 20 dan 30 HST. Pemberian dosis mulsa terbaik dijumpai pada dosis mulsa ampas tebu 15 ton/ha. Hal ini diduga pemberian dosis mulsa ampas tebu 15 ton/ha dapat menjaga kelembaban tanah dan suhu tanah sehingga ketersediaan air mendukung pertumbuhan tanaman bawang merah. Air dapat mempermudah pengangkutan hara dalam tanah sehingga unsur hara yang tersedia dapat diserap oleh tanaman untuk pertumbuhan tanaman bawang merah. Hal ini sesuai dengan Mulyatri (2003) menyatakan pemberian mulsa dapat mencegah kehilangan air, menjaga kelembaban dan suhu tanah sehingga menciptakan kondisi lingkungan yang sesuai bagi pertumbuhan tanaman.

Tabel 1. Rata-rata pertumbuhan dan hasil tanaman bawang merah akibat dosis mulsa ampas tebu

\begin{tabular}{|c|c|c|c|c|c|}
\hline \multicolumn{2}{|c|}{ Parameter yang diamati } & \multicolumn{3}{|c|}{ Dosis mulsa ampas tebu (ton/ha) } & \multirow{2}{*}{$\begin{array}{l}\mathrm{BNJ} \\
0,05\end{array}$} \\
\hline & & $5\left(D_{1}\right)$ & $10\left(\mathrm{D}_{2}\right)$ & $15\left(\mathrm{D}_{3}\right)$ & \\
\hline \multirow{3}{*}{$\begin{array}{l}\text { Tinggi tanaman } \\
(\mathrm{cm})\end{array}$} & $10 \mathrm{HST}$ & $9,29^{b}$ & $6,91^{\mathrm{a}}$ & $10,80^{b}$ & 2,04 \\
\hline & $20 \mathrm{HST}$ & $21,51^{\mathrm{a}}$ & $21,62^{\mathrm{a}}$ & $24,33^{b}$ & 2,07 \\
\hline & $30 \mathrm{HST}$ & $24,69^{\mathrm{a}}$ & $25,76^{\mathrm{a}}$ & $28,40^{\mathrm{b}}$ & 2,41 \\
\hline \multicolumn{2}{|c|}{ Jumlah anakan (anakan) } & 6,27 & 6,31 & 6,42 & - \\
\hline \multicolumn{2}{|c|}{ Jumlah umbi (siung) } & 6,11 & 6,24 & 6,38 & - \\
\hline \multicolumn{2}{|c|}{ Diameter Umbi (mm) } & 19,70 & 19,78 & 19,31 & - \\
\hline \multicolumn{2}{|c|}{ Bobot berangkasan basah (g) } & 3,29 & 3,54 & 2,90 & - \\
\hline \multicolumn{2}{|c|}{ Bobot basah umbi (g) } & 25,04 & 25,76 & 28,37 & - \\
\hline \multicolumn{2}{|c|}{ Bobot brangkasan kering (g) } & 3,23 & 3,51 & 2,85 & - \\
\hline \multicolumn{2}{|c|}{ Bobot keringumbi (g) } & 22,89 & 23,96 & 27,13 & - \\
\hline \multicolumn{2}{|c|}{ Potensi hasil (ton/ha) } & 3,32 & 2,86 & 3,63 & - \\
\hline
\end{tabular}

Keterangan : Angka yang diikuti oleh huruf yang sama pada baris yang sama berbeda tidak nyata pada taraf peluang $5 \%\left(\mathrm{BNJ}_{0,05}\right)$.

Pemberian mulsa dapat melindungi tanah dari daya rusak butiran hujan, meningkatkan penyerapan air oleh tanah, memelihara temperatur, kelembaban tanah, memelihara kandugan bahan organik tanah dan mengendalikan pertumbuhan gulma sehingga keadaan tanah menjadi lebih optimal bagi pertumbuhan tanaman. Hayati et al. (2010) menyatakan bahwa akibat pemberian mulsa jerami, mulsa ampas tebu dan mulsa sekam padi dapat meningkatkan pertumbuhan dan produksi tanaman jagung. Hasil terbaik diperoleh dengan pemberian mulsa sekam padi kemudian disusul oleh pemberian mulsa ampas tebu dan produksi terendah dihasilkan dengan pemberian mulsa jerami.

Hasil penelitian menunjukkan bahwa dosis mulsa ampas tebu berpengaruh tidak nyata terhadap jumlah anakan per rumpun, jumlah umbi per rumpun, bobot basah umbi, bobot kering umbi, serta potensi hasil per hektar. Namun 15 ton/ha cenderung memberikan hasil yang lebih baik dari 10 ton/ha dan 5 ton/ha. Sedangkan diameter umbi, bobot berangkasan basah, dan bobot berangkasan kering 10 ton/ha cenderung memberikan hasil yang lebih baik dari 5 ton/ha dan 15 ton/ha.

Hasil penelitian menunjukkan bahwa mulsa ampas tebu berpengaruh tidak nyata terhadap jumlah umbi per rumpun, jumlah anakan per rumpun, diameter umbi, bobot 
berangkasan basah, bobot basah umbi, bobot berangkasan kering, bobot kering umbi, serta potensi hasil per hektar bawang merah. Keadaan ini merupakan bukti bahwa mulsa ampas tebu tidak dapat memenuhi sebagian besar dari manfaat bahan mulsa yang baik. Parlindungan (2015) menyatakan ampas tebu sebagai mulsa tidak berpengaruh nyata terhadap porositas dan kadar air volume tanah maupun terhadap produksi biji kedelai varietas Burangrang.

Penelitian ini terlihat jelas bahwa ampas tebu bukan bahan mulsa yang baik karena mulsa ampas tebu belum mampu meningkatkan hasil tanaman bawang merah. Hal ini diduga karena dipengaruhi oleh faktor lingkungan yang tidak mendukung. Pada saat penelitian berlangsung cuaca lingkungan sering kali terjadi hujan sehingga tanaman bawang merah sedikit mendapatkan cahaya matahari yang merupakan sumber utama energi yang dipergunakan dalam proses fotosintesis tanaman bawang merah. Apabila proses fotosintesis terganggu maka dapat mempengaruhi hasil tanaman bawang merah. Sesuai dengan Suryadi et al. (2002) menyatakan lingkungan yang tidak mendukung dapat menyebabkan terhambatnya pertumbuhan dan hasil suatu tanaman.

\section{Pengaruh Varietas terhadap Pertumbuhan dan Hasil Tanaman Bawang Merah}

Hasil uji $\mathrm{F}$ menunjukkan bahwa varietas berpengaruh sangat nyata terhadap semua parameter pengamatan yaitu tinggi tanaman umur 10, 20, 30 HST, jumlah anakan per rumpun, jumlah umbi per rumpun, diameter umbi, bobot berangkasan basah, bobot basah umbi, bobot berangkasan kering, bobot kering umbi dan potensi hasil per hektar.

Tabel 2. Rata-rata pertumbuhan dan hasil tanaman bawang merah akibat dosis mulsa ampas tebu

\begin{tabular}{|c|c|c|c|c|c|}
\hline \multicolumn{2}{|c|}{ Parameter yang diamati } & \multicolumn{3}{|c|}{ Varietas bawang merah } & \multirow{2}{*}{$\begin{array}{l}\mathrm{BNJ} \\
0,05\end{array}$} \\
\hline & & $\begin{array}{c}\text { Bima Brebes } \\
\left(\mathrm{V}_{1}\right)\end{array}$ & $\begin{array}{c}\text { Vietnam } \\
\left(\mathrm{V}_{2}\right)\end{array}$ & $\begin{array}{c}\text { Bangkok } \\
\left(\mathrm{V}_{3}\right)\end{array}$ & \\
\hline \multirow{3}{*}{$\begin{array}{l}\text { Tinggi tanaman } \\
(\mathrm{cm})\end{array}$} & $10 \mathrm{HST}$ & $4,96^{\mathrm{a}}$ & $12,89^{\mathrm{c}}$ & $9,16^{\mathrm{b}}$ & 2,04 \\
\hline & $20 \mathrm{HST}$ & $19,09^{\mathrm{a}}$ & $27,07^{\mathrm{c}}$ & $21,78^{b}$ & 2,07 \\
\hline & $30 \mathrm{HST}$ & $23,27^{\mathrm{a}}$ & $30,47^{\mathrm{b}}$ & $25,11^{\mathrm{a}}$ & 2,41 \\
\hline \multicolumn{2}{|c|}{ Jumlah anakan (anakan) } & $7,16^{\mathrm{b}}$ & $5,89^{\mathrm{a}}$ & $5,96^{\mathrm{a}}$ & 0,87 \\
\hline \multicolumn{2}{|c|}{ Jumlah umbi (siung) } & $7,13^{b}$ & $5,69^{\mathrm{a}}$ & $5,91^{\mathrm{a}}$ & 0,88 \\
\hline \multicolumn{2}{|c|}{ Diameter Umbi (mm) } & $15,64^{\mathrm{a}}$ & $22,06^{\mathrm{b}}$ & $21,09^{b}$ & 1,81 \\
\hline \multicolumn{2}{|c|}{ Bobot berangkasan basah (g) } & $1,13^{\mathrm{a}}$ & $4,89^{\mathrm{c}}$ & $3,71^{\mathrm{b}}$ & 0,89 \\
\hline \multicolumn{2}{|c|}{ Bobot basahumbi (g) } & $17,91^{\mathrm{a}}$ & $34,16^{\mathrm{c}}$ & $27,10^{\mathrm{b}}$ & 5,14 \\
\hline \multicolumn{2}{|c|}{ Bobot brangkasan kering (g) } & $1,09^{\mathrm{a}}$ & $4,85^{\mathrm{c}}$ & $3,65^{\mathrm{b}}$ & 0,91 \\
\hline \multicolumn{2}{|c|}{ Bobot keringumbi (g) } & $15,40^{\mathrm{a}}$ & $32,42^{b}$ & $26,17^{\mathrm{b}}$ & 6,65 \\
\hline \multicolumn{2}{|c|}{ Potensi hasil (ton/ha) } & $1,77^{\mathrm{a}}$ & $5,19^{b}$ & $1,10^{\mathrm{a}}$ & 1,10 \\
\hline
\end{tabular}

Keterangan : Angka yang diikuti oleh huruf yang sama pada baris yang sama berbeda tidak nyata pada taraf peluang $5 \%\left(\mathrm{BNJ}_{0,05}\right)$.

Hasil penelitian menunjukkan bahwa varietas bawang merah berpengaruh sangat nyata terhadap semua peubah yang diamati. Hal ini diduga varietas tersebut dipengaruhi oleh faktor genetik masing-masing varietas. Sesuai dengan penelitian Budianto et al. (2009) menyatakan 
bahwa karakter umbi bawang merah banyak dipengaruhi oleh faktor genetik dan sedikit dipengaruhi oleh lingkungan. Awas et al. (2010) juga menyatakan setiap varietas memberikan respon yang berbeda karena setiap varietas memiliki pertumbuhan akar dan daun yang berbeda walaupun ditanam pada tanah yang sama.

Hasil penelitian menunjukkan varietas terbaik dijumpai pada varietas Vietnam dibandingkan dengan varietas Bangkok dan Bima Brebes. Perbedaan daya tumbuh antar varietas yang berbeda sangat ditentukan oleh faktor genetiknya dan juga morfologi tanaman. Morfologi tanaman memberikan respon terhadap intensitas cahaya. Varietas Vietnam memiliki bentuk daun bulat pipih berbeda dari varietas Bima brebes dan Bangkok yaitu silindris berlubang. Jumlah luas daun menjadi penentu utama kecepatan pertumbuhan tanaman. Semakin lebar luas daun suatu tanaman maka proses fotosintesis semakin tinggi sehingga dapat memenuhi kebutuhan tanaman. Sesuai dengan pernyataan Marjenah (2001) tanaman yang mempunyai daun-daun luas yang lebih banyak akan mempunyai pertumbuhan yang lebih cepat. Itue et al. (2011) menambahkan bahwa potensi gen dari suatu tanaman akan lebih maksimal jika didukung oleh faktor lingkungan. Hal ini diduga varietas Vietnam mampu beradaptasi baik dengan lingkungan dibandingkan dengan varietas Bangkok dan Bima Brebes.

Pengamatan tinggi tanaman umur 10, 20 dan 30 HST tanaman bawang merah tertinggi dijumpai pada varietas Vietnam berbeda nyata dengan varietas Bangkok dan Bima Brebes. Jumlah anakan per rumpun dan jumlah umbi per rumpun tanaman bawang merah tertinggi dijumpai pada varietas Bima Brebes berbeda nyata dengan varietas Bangkok dan varietas Vietnam. Sedangkan bobot berangkasan basah, bobot basah umbi, bobot berangkasan kering, bobot kering umbi, diameter umbi dan potensi hasil per hektar tanaman bawang merah tertinggi dijumpai pada varietas Vietnam berbeda nyata dengan varietas Bangkok dan Bima Brebes.

\section{Pengaruh Interaksi antara Dosis Mulsa Ampas Tebu dan Varietas terhadap Pertumbuhan dan Hasil Tanaman Bawang Merah}

Hasil penelitian menunjukkan bahwa terdapat interaksi yang tidak nyata antara dosis mulsa ampas tebu dengan varietas bawang merah terhadap semua peubah pertumbuhan dan hasil tanaman bawang merah. Hal ini diduga karena perbedaan pertumbuhan dan hasil tanaman bawang merah akibat dosis mulsa ampas tebu pada taraf dosis yang berbeda tidak dipengaruhi oleh perbedaan varietas bawang merah dan begitu juga dengan perbedaan perlakuan varietas bawang merah tidak dipengaruhi oleh perlakuan dosis mulsa ampas tebu.

\section{KESIMPULAN DAN SARAN}

\section{Kesimpulan}

Dosis mulsa ampas tebu berpengaruh sangat nyata terhadap tinggi tanaman umur 10, 20 dan 30 HST, berpengaruh tidak nyata terhadap jumlah umbi per rumpun, jumlah anakan per rumpun, diameter umbi, bobot berangkasan basah, bobot basah umbi, bobot berangkasan kering, bobot kering umbi, serta potensi hasil bawang merah. Pertumbuhan dan hasil tanaman bawang merah terbaik dijumpai pada dosis mulsa ampas tebu 15 ton/ha. Perlakuan varietas berpengaruh sangat nyata terhadap semua peubah yang diamati. Penggunaan varietas terbaik dijumpai pada varietas Vietnam. Terdapat interaksi yang tidak nyata antara dosis mulsa ampas tebu dengan varietas terhadap pertumbuhan dan hasil tanaman bawang merah. 


\section{Saran}

Perlu dilakukan penelitian lanjutan untuk mengetahui dosis mulsa ampas tebu yang tepat terhadap varietas bawang merah. Penggunaan dosis mulsa ampas tebu dapat ditingkatkan untuk melihat pengaruhnya terhadap varietas bawang merah.

\section{DAFTAR PUSTAKA}

Awas, G., Abdissa dan T. Tolesa. 2010. Pengaruh jarak dan baris terhadap hasil tiga varietas bawang (Allium cepa L.) J. Hortikultura dan Kehutanan. 2 (7) : 7-11.

Badan Pusat Statistik dan Direktorat Jendral Hortikultura. 2016. Produksi Bawang Merah. [22 Desember 2017].

Basuki, S. R. 2005. Daya hasil dan preferensi petani terhadap varietas bawang merah lokal dan berbagai daerah, laporan hasil penelitian APBN 2005-ROPP DI.

Budianto, Aris, Ngawit dan Sudika. 2009. Keragaman genetik beberapa sifat dan seleksi klon berulang sederhana pada tanaman bawang merah kultivar ampenan. J. Crop Agro. 2 (1) : $28-38$.

Direktorat Jendral Hortikultura. 2014. Konsumsi Bawang Merah. [ 2 Mei 2017 ].

Hayati, E., A.H. Ahmad dan C.T. Rahman. 2010. Respon jagung manis (Zea mays, Sacharata SHOUT) terhadap penggunaan mulsa dan pupuk organik. J. Agrista. 14 (1) : 21-25.

Husin, A. A. 2007. Pemanfaatan limbah untuk bahan bangunan. http://www.kimpraswil. go.id/balitbang/puskim/Homepage\%20Modul\%202003/modulc1/MAKALAH\%20C 13.pdf . [22 Januari 2018]

Iteu, M., Hidayat, S. Putrasameja dan C. Azmin. 2011. Persiapan pelepasan varietas bawang merah umbi dan TSS. Dalam Mehran, K. Ely dan Sufardi. Pertumbuhan dan hasil beberapa varietas bawang merah pada tanah aluvial akibat pemberian berbagai dosis pupuk NPK. J. Floratek. 11 (2) : 117-133.

Marjenah. 2001. Pengaruh cahaya terhadap pertumbuhan. https://chipeuw2009. wordpress.com/2010/12/10/pengaruh-cahaya-terhadap pertumbuha/. [21 Desember 2017].

Mulyatri. 2003. Peranan pengolahan tanah dan bahan organik terhadap konservasi tanah dan air. J. Ilmu Pertanian. 13 (1) : 65-76.

Novayana, D., S. Rosita dan B. Asil. 2015. Respon pertumbuhan dan produksi bawang merah terhadap jenis mulsa dan pupuk kandang ayam. J. Online Agroteknologi. 3 (2) : 446457.

Parlindungan, L. dan B. Tampubolon. 2015. Pengolahan Tanah dan Mulsa Ampas Tebu Memperbaiki Porositas, Kadar Air Tanah dan Produksi Biji Kedelai pada Ultisol Simalingkar. Skripsi. Fakultas Pertanian, Universitas HKBP. Hal 78-89.

Suriani, N. 2012. Bawang Bawa Untung. Budidaya Bawang Merah dan Bawang Putih. Cahaya Atma Pustaka, Yogjakarta.

Suryadi, Luthfy, K. Yenni dan Gunawan. 2002. Evaluasi karakter pertumbuhan bahan dan hasil 17 genotipe plasma nutfah bayam cabut. Bulettin Plasma Nutafah. 8 (1) : 19-22. 